\title{
Utilizing Fishermen Knowledge and Expertise: Keys to Success for Collaborative Fisheries Research
}

Noëlle Yochum

Richard M. Starr

\section{Dean E. Wendt}

ABSTRACT: Collaborative fisheries research provides a mechanism for integrating the unique knowledge, experience, and skills of fishermen and scientists. It is a joint intellectual endeavor that begins with the inception of a project and continues until its final stages, with each group having mutual investment in-and ownership of the project. Collaborative fisheries research promotes communication and trust among fishermen, scientists, and managers and can provide much-needed scientifically valid data for fisheries management. It can enhance federal and state management data collection programs, which span broad sections of coastline, by increasing the ability to detect changes in local metapopulations that may be overfished or underutilized. We describe a methodology for conducting collaborative fisheries surveys and apply it to marine protected areas along the central California coast. During a series of workshops in 2006, attended by members of the fishing, academic, environmental, and management communities, protocols were established for conducting hook-and-line surveys collaboratively with commercial passenger fishing vessel captains and volunteer recreational anglers. The protocols have been implemented annually since 2007. This case study highlights the effectiveness of - and the essential steps in-developing our collaborative fisheries research and monitoring projects.

\section{Introduction}

Cooperative research has increasingly gained momentum as an effective tool for generating fisheries data. "Cooperative research" describes research with any degree of partnership among various parties, including "commercial and recreational fishermen, fishing industry groups, nongovernmental organizations (NGOs), Sea Grant, state resource agencies, and universities" (National Research Council [NRC] 2004). Within cooperative research exists a continuum from strictly cooperative to fully collaborative, with each indicating a different level of involvement from participating groups. An example of cooperative research is chartering a fishing vessel to conduct surveys. At the other end of the spectrum, a collaborative program would incorporate fishermen into "all phases of the research process including formulation of the research question and generation of the hypothesis" (NRC 2004).

\section{Uso del conocimiento y experiencia de los pescadores: clave del éxito en la in- vestigación pesquera colaborativa}

RESUMEN: la investigación pesquera colaborativa brinda un mecanismo para integrar el conocimiento, experiencia y habilidades de pescadores y científicos. Representa una tarea intelectual conjunta que comienza con una propuesta de proyecto y hacia sus etapas finales, los grupos cuentan con una inversión mutua en $-y$ siendo propietarios del- proyecto mismo. La investigación pesquera colaborativa promueve la comunicación y confianza entre pescadores, científicos y manejadores así como también puede proveer los tan necesitados datos, científicamente validados, para el manejo pesquero. Esto también puede mejorar los programas federales y estatales de colección y manejo de datos, los cuales abarcan grandes extensiones de la línea costera, a través del mejoramiento de las habilidades para detectar los cambios en metapoblaciones locales que pueden estar sobreexplotadas o subutilizadas. Se describe la metodología para llevar a cabo sondeos colaborativos en pesquerías y su aplicación en Áreas Marinas Protegidas a lo largo de la porción central de California. Durante una serie de talleres de trabajo realizados en 2006, a los que atendieron miembros del sector pesquero, académico, ambiental y de manejo de comunidades, se establecieron los protocolos para conducir de forma conjunta encuestas a los capitanes de embarcaciones pesqueras y pescadores voluntarios de embarcaciones recreativas. Los protocolos se han implementado anualmente desde 2007. Este caso de estudio destaca la efectividad del $-y$ los pasos fundamentales para el- desarrollo de la investigación pesquera colaborativa y de proyectos de monitoreo.

The advantages of cooperation have been verified by numerous research projects. Benefits include reduced costs (Harms and Sylvia 2000; Johnson and van Densen 2007; Hart et al. 2008), increased sampling frequency, the ability to address immediate issues (as opposed to conventional data collection methods that may not recognize immediate data needs; Conway and Pomeroy 2006), and the generation of fine-scale data (Harms and Sylvia 2000; Johnson and van Densen 2007) that can be used in subpopulation-level assessments. Assessments of fish populations are often done over a broad geographic scale due to logistical and funding restrictions. Without fine-scale information there is the potential to mask the 
existence of metapopulations (spatially discrete populations of a species) and localized overfishing or underutilization of fisheries resources (Tuckey et al. 2007). Moreover, surveying with more passive fishing gear-such as hook-and-line or trapscan be effective at catching cryptic or crevice-dwelling species that are not susceptible to traditional survey methods (e.g., trawling, visual surveys). Fishermen can also provide fresh perspectives on emerging or pressing issues (Gilden and Conway 2002); given their familiarity with local ecosystems, they are well positioned to detect fine-scale changes in fish populations (Daw et al. 2011) and to serve as an early warning network (Rochet et al. 2008).

In addition to the enhancement of fisheries data, cooperative research provides an opportunity to build, rebuild, or strengthen communication and trust among industry members, scientific groups, and/or resource managers (Conway and Pomeroy 2006; Hartley and Robertson 2008; Feeney et al. 2010). Increased communication can minimize negative relationships (such as disregard for regulations) between fishing communities and management agencies that often occur because of distrust for management decisions (Kaplan and McCay 2004; Hartley and Robertson 2006; Johnson and van Densen 2007). Cooperative research can reduce the suspicion and controversy that stems from opaque management, wherein the assessment process is incomprehensible or hidden from industry members, and from discrepancies between scientific inferences and fishermen's direct observations (Gilden and Conway 2002; Kaplan and McCay 2004). Cooperative research diminishes these barriers by enhancing transparency and communication (Gilden and Conway 2002; Kaplan and McCay 2004; Johnson and van Densen 2007) and fostering mutual education and knowledge exchange (Hartley and Robertson 2008; Johnson 2010). This is valuable because members of the fishing industry are more likely to trust science when they understand how it works (Johnson and van Densen 2007) and if they are allowed to participate in it (NRC 2004). In addition, involving fishermen in the research process is a mechanism to validate fishermen's role in the fishery, to provide an avenue for greater ownership and investment in the fishery (Gilden and Conway 2002; Jones et al. 2007; Wells et al. 2010), and to facilitate stewardship. Cooperative research also provides an opportunity for scientists to invest in local fishing communities (Gilden and Conway 2002; Hartley and Robertson 2006).

Although there are many benefits to cooperative research, there are also potential drawbacks. Attitudes toward cooperation from the fishing, scientific, and management communities can be both positive and negative (Harms and Sylvia 2000; Silver and Campbell 2005; Hartley and Robertson 2008). Whereas some fishermen feel that it is important for their expertise and knowledge to be incorporated into scientific research, there is also skepticism and fear within the fishing community that the data that they help to produce will be used against them and will harm the fishery or their way of life (Silver and Campbell 2005; Conway and Pomeroy 2006; Steneck 2006; Jones et al. 2007; Hartley and Robertson 2008; Hartley and Robertson 2009). Conversely, some resource managers fear that fishermen may provide unreliable or deliberately falsified data (Harms and Sylvia 2000; Silver and Campbell 2005). An additional hindrance to cooperation is a potential increase in research costs (Gilden and Conway 2002), particularly if the outcome is inferior to that which could have been produced by scientists alone (Schumann 2010) and thus a consequence could arise whereby funding for research might prove difficult (NRC 2004).

Collaborative research, as opposed to strictly cooperative research, can better address these obstacles and communication barriers. Because collaboration involves members of the fishing industry in each phase of research-including the generation of research questions, developing sampling protocols, collecting data, and analyzing, interpreting, and disseminating results (Wendt and Starr 2009) — there are more opportunities for communication, mutual education, and trust building. In addition, by involving fishermen in each phase, they become more invested in the project and have more confidence in the data and the results (NRC 2004). Truly collaborative research also provides an opportunity for scientists to reveal the rigor behind scientific design and fisheries assessments (Gilden and Conway 2002), removing the "black box" feel toward scientific data collection. It is possible, without excessive effort, to convey concepts of scientific principles and important aspects of scientific design (e.g., standardized methods, proper data recording, etc.) in a comprehensive manner and to demonstrate how this relates to the quality of results. Furthermore, it provides an opportunity for scientists to acknowledge the unique skills and experience that fishermen possess.

In this article, we describe a methodology for successfully creating and performing a collaborative research survey, using a case study of fisheries monitoring of central California marine protected areas (MPAs). In doing so, we outline eight specific steps that should be followed to ensure a successful collaborative research effort.

\section{A Methodological Framework for Establishing a Collaborative Research Survey}

In 2007, in accordance with the 1999 California Marine Life Protection Act (MLPA; California Department of Fish and Game [CDFG] 2008), 29 MPAs were established along the central California coast, from Pigeon Point to Point Conception (Figure 1). The closed areas encompassed $528 \mathrm{~km}^{2}, 40 \mathrm{~km}^{2}$ of which were designated as "no take" state marine reserves (California Marine Life Protection Act Initiative [CMLPA] 2007). The Central Coast MPAs inaugurated the MLPA plan to establish MPAs along the $2,000-\mathrm{km}$ coast of California one 


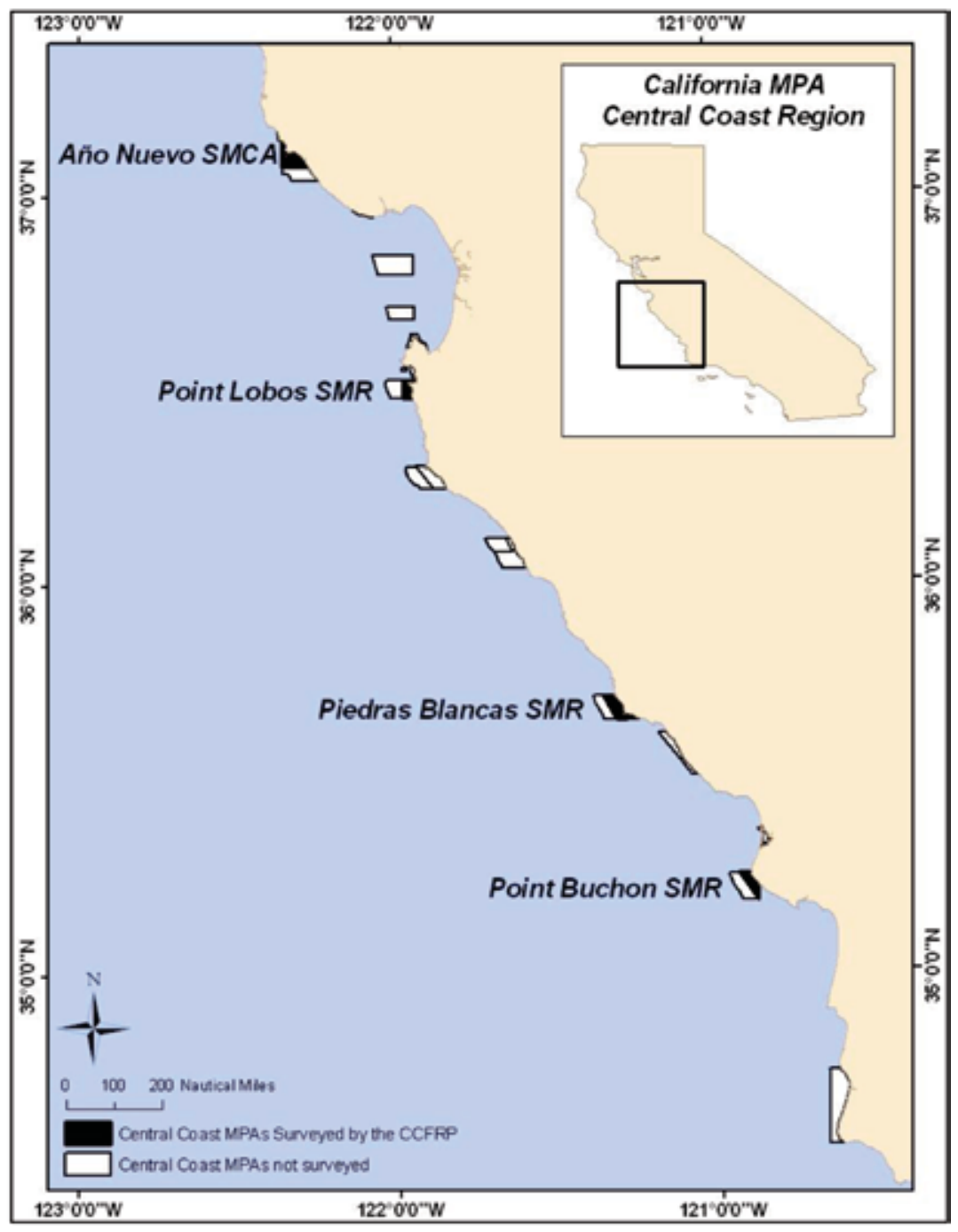

Figure 1. California central coast marine protected areas (MPAs) adopted by the California Department of Fish and Game Commission in 2007. The four that were surveyed by the California Collaborative Fisheries Research Program (CCFRP) are the Año Nuevo State Marine Conservation Area (SMCA) and the Point Lobos, Piedras Blancas, and Point Buchon State Marine Reserves (SMRs).
In 2006, in anticipation of the implementation of these MPAs and to promote collaborative research along the Pacific coast, the California Collaborative Fisheries Research Program (CCFRP) was formed. The initial goal of the CCFRP was to establish a baseline that could be used to assess temporal changes in the fish populations within the newly designated MPAs (Wendt and Starr 2009). During a series of workshops attended by members of the fishing, academic, environmental, fishery management, and NGO communities, survey goals and sampling protocols were established. Since then, these protocols have been implemented at sea each year (2007-2010).

Through our previous cooperative and collaborative research projects and the research and monitoring implemented by the CCFRP, we have identified eight key steps for successfully developing and implementing collaborative fisheries research (Figure 2). These steps are detailed in the following sections, in approximately chronological order.

\section{Create a Solid Foundation: Identify Collaborators and Build Relationships}

It is valuable to create a strong foundation on which to develop a collaborative project. The success of the project depends on trust and sense of partnership (Pinto da Silva and Kitts 2006). Helpful tasks in creating this foundation include identifying willing and interested collaborators and building personal relationships. Open communication about perceptions and concerns should begin at this step. It is also useful to recognize and respect cultural differences from the beginning and to acknowledge the various perspectives that exist.

For widespread acceptance of the results of region at a time, starting with the Central Coast (established in 2007), followed by the North Central Coast (in 2010), South Coast (2011), North Coast (in progress), and finishing with San Francisco Bay (process beginning; CDFG 2011). The procedure for designing and implementing MPAs in each of these regions is thorough and time intensive; it involves a variety of stakeholders and is open to the public. Efforts are made to reach a compromise among stakeholder groups, yet tension remains high as each group argues for a design that best suits their interests. Central California consists of relatively small historic fishing communities, with primarily recreational and some nearshore commercial fishing activity. Though ports in this area are not industrial, fisheries management decisions affect a large number of people. the collaborative research, it is important that the scope of collaborators be as broad as possible while still being appropriate to the given research need. This can be accomplished by involving both primary and secondary collaborators (Maienschein 1993); the former are those who will work together during most steps of the research process and the latter are those who will be involved on a less substantial basis but will still contribute to aspects of the research (e.g., advising on protocol development). Collaborators may include fishermen, scientists, members of NGOs, and anyone (including the general public) who is supportive of the concept and can give feedback on the survey design and results. In addition, it is advisable to include resource managers as collaborators so that the project can be linked to a management data need. 


\section{Keys to Success}

\section{Barriers to Success}

\begin{tabular}{|l|}
\hline \multicolumn{1}{|c|}{ Create a Solid Foundation } \\
\hline - Include collaborators that are enthusiastic about the project \\
- Broaden the scope of collaborators \\
- Discuss perspectives and concerns openly
\end{tabular}

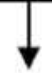

\section{Define Success}

- Ensure that goals are clear and agreed upon by collaborators

- Determine what "success" means

- Address timely issues and management needs

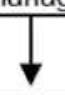

\section{Define Roles}

-Acknowledge the knowledge and skills of each collaborator; utilize these to their full capacity

- Communicate individual constraints

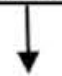

\section{Define the Scope}

- Select locations that are relevant to management and are feasible

- Allow the extent of the project to reflect available resources

\section{Develop a Sampling Plan}

- Design research that utilizes the expertise of all collaborators

- Develop protocols using a facilitated workshop format

- Train all participants before implementation

\section{Implement the Project}

- Designate project leads for "on-the-water" decision making

- Execute protocols collaboratively in a standardized manner

- Be prepared for unexpected field conditions

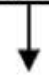

\section{Evaluate the Project}

- Be rigorous in data organization and evaluation

- Share interpretations about the results; build consensus

- Encourage $1^{\circ}$ and $2^{\circ}$ collaborators to evaluate survey design

\section{Communicate the Results}

- Outreach to the public, to all collaborators and their respective communities through appropriate mediums and language

- Continue communication beyond project completion
- Not providing sufficient incentives

- Not acknowledging differences in culture

- Excluding potential collaborators (e.g., community leaders)

Creating goals that are too narrow, too

broad, or infeasible

- Having unrealistic expectations

- Not listening to all collaborators' input

- Not dividing responsibilities proportionately or appropriately

- Ignoring time, financial, and logistic constraints

Designing a survey that is not cost effective or does not reflect project goals

- Ignoring input from collaborators

Being inflexible

- Not assigning decision making authority

- Not training before executing protocols

Not making the data available to

collaborating fishermen

- Not being transparent about data analysis

- Ignoring feedback about surveys

Not communicating with managers about ways to implement the data

- Using the data to advocate for a particular management alternative

Figure 2. Eight key steps for developing and implementing collaborative fisheries research and potential barriers to success. 
For the CCFRP MPA program, the primary collaborators include scientists (from both academic institutions and management agencies) and members of the fishing community who are enthusiastic about the research and want to play a central role in the project. In addition to their interest, collaborating fishermen were initially selected with respect to the species we targeted, which influenced our vessel requirements, sampling gear, and fishing protocols. Additional requirements for collaborators include licenses, permits, and insurance. Because nearshore fishes along the central California coast consist primarily of cryptic species, hook-and-line fishing gear was selected as the survey sampling gear. Commercial passenger fishing vessel (CPFV; i.e., charter boat for sport fishing) captains and local recreational anglers were therefore identified as ideal collaborators.

Members of central California fishing communities as well as those of resource management, academic, NGOs, other fishing groups, and the public were invited to workshops to discuss the project and to help identify collaborators. The workshops were always convened and run by a professional facilitator, who helped guide the meetings and acted as a neutral party to help build consensus among participants. At the outset we encouraged participants to share their perspectives on the status of the resource, what they could contribute to the research process, and their apprehensions. Additionally, in order to foster an exchange of ideas and to understand the discrepancies in perspectives, phone calls and in-person meetings with collaborators were made outside of the workshops. Collaborators' concerns were then addressed and compromises and adjustments were made when the result would not affect the scientific integrity of the project (e.g., one captain did not want to submerge any scientific equipment [temperature sensor, Secchi disc] frequently or at the start of fishing for fear that it would scare off the fish).

\section{Define Success: Identify Program Goals and Objectives}

Project success requires that clear and realistic goals and objectives be established early on (Wiber et al. 2009). The goals should be neither too broad nor too narrow in scope (Harms and Sylvia 2000). Also, the project must address relevant and timely issues. In addition to establishing the project goals, it is also beneficial to discuss the desired final products and what "success" for the project means to each collaborator, as well as what will be done with the data-where it will go, who will use it, how it will be used, and how the resultant information will be communicated. For these reasons, it is useful to include management agency scientists and staff as primary collaborators. It is important that all participants have input, that everyone's input be considered, and that each collaborator be treated as an equal in the process in order to build trust (Johnson and van Densen 2007).
To establish CCFRP research objectives, the identified collaborators convened during a second series of workshops, which were scheduled at convenient locations and at times that were accommodating to the fishermen's schedules. During the workshops, specific project questions, hypotheses, and goals were identified, with the intention of having them reflect the collective interest of all collaborators. Sufficient time was allotted at the workshops for each collaborator to comment so that their concerns and ideas were discussed. As a result of these workshops, the goals of the CCFRP MPA surveys (Wendt and Starr 2009) were determined to be as follows: to (1) utilize the expertise of both scientists and fishermen to develop and conduct a scientifically sound research program; (2) collect data to assess the impact of marine protected areas on nearshore fish assemblages; (3) collect data for federal stock assessments of nearshore species; (4) engage the public in research and education about marine conservation and stewardship; and (5) open up a dialogue among stakeholders regarding California's MPAs.

\section{Define Roles: Discuss and Delineate Responsibilities}

It is helpful to acknowledge and utilize, to their full capacity, the unique skill sets and knowledge bases of each collaborator. In order to do this, the roles and responsibilities of each collaborator must be defined early on (Johnson and van Densen 2007), including assignment of financial and time obligations, responsibility for securing funds, and responsibility for data management, analysis, and dissemination. Scientists are best qualified to lead in the discussion and planning of sampling design and data requirements, as well as data analysis and modeling capabilities. In contrast, fishermen are uniquely qualified to identify appropriate sampling methods (i.e., fishing techniques), locate fish, account for environmental variables that may influence fish distributions and aggregations (e.g., seasonal climate changes), assume responsibility for the safety of crew members when at sea, and plan for project expenses.

Responsibilities for the CCFRP project were delegated according to each collaborator's skills. For the MPA surveys, scientists were responsible for organizing and overseeing the survey operations, recording data, organizing volunteers, providing the standardized fishing tackle, organizing and synthesizing the data, and procuring funds to run the sampling program. Collaborating captains provided rods, reels, and bait; transported science crew and volunteers to and from the survey sites; and identified optimal fishing locations within sampling grid cells. Volunteer anglers were responsible for catching the fishes (Figure 3). Deckhands assisted the science crew with tasks such as fish handling and release (to minimize injury to the fish), ensured that the tackle was standardized, helped the volunteers, informed the scientists when seals or sea lions were present (which may affect total catch rate), and assisted the crew in collecting Secchi depth and water temperature measurements. 

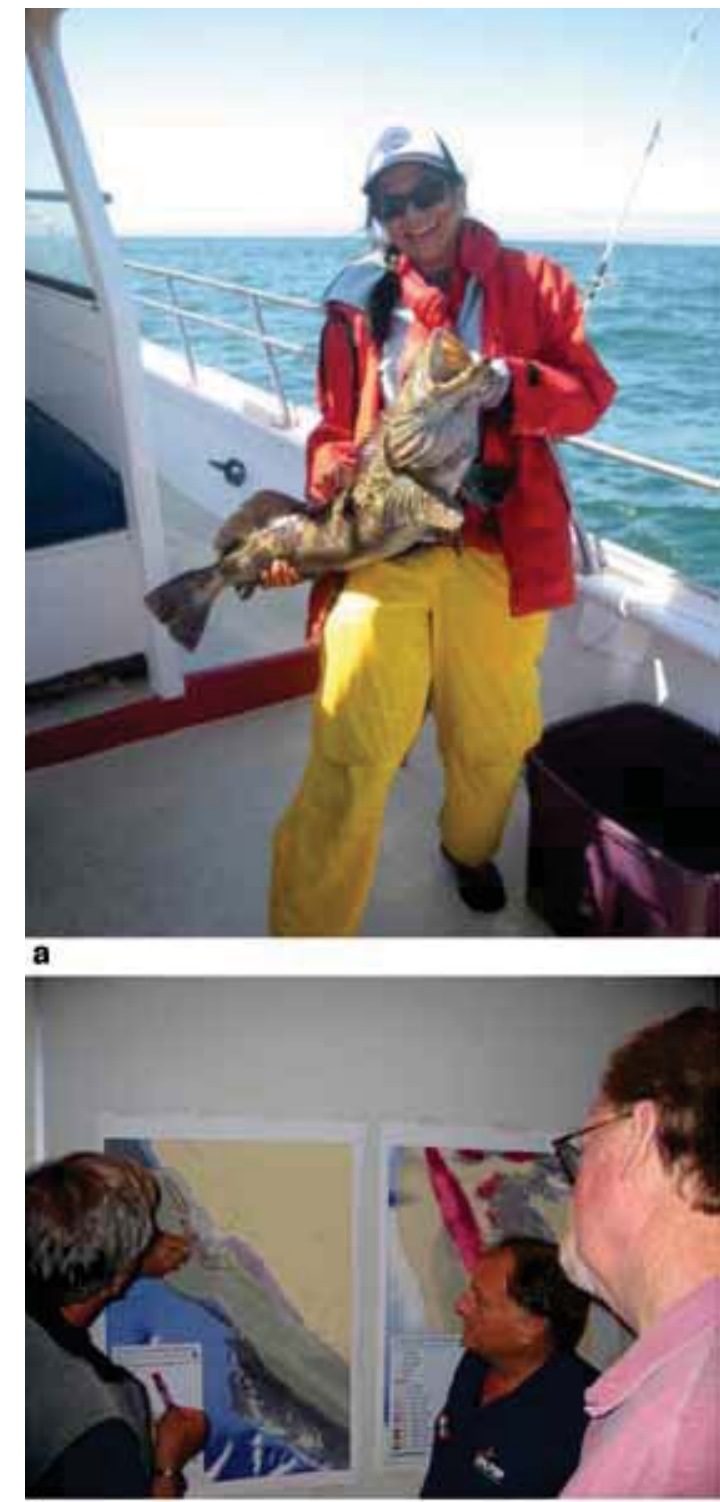

b

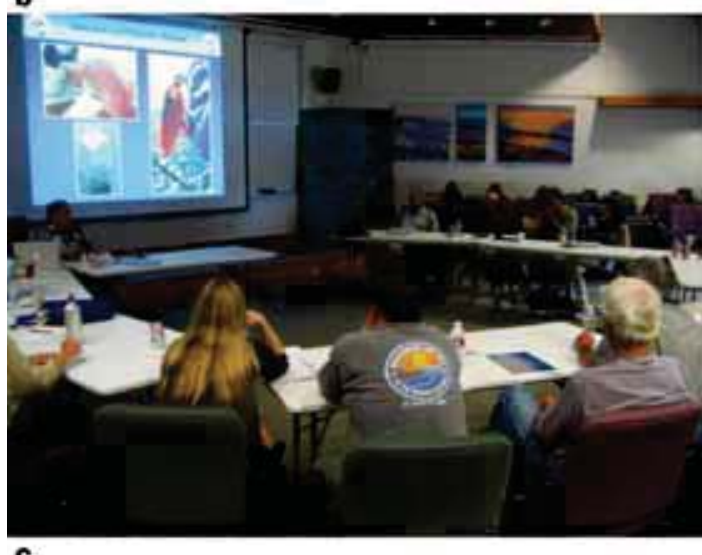

c

Figure 3. Photographs of (a) a volunteer recreational angler during a CCFRP survey, (b) a planning workshop where we worked with CPFV captains to determine survey areas, and (c) a postsurvey workshop in which we reviewed the protocols and data with collaborators. Photo credits: Noëlle Yochum (A), Don Maruska (B and C).

\section{Define the Scope: Determine Survey Sites and Sampling Intensity}

In determining the location and extent of a research project, logistical, financial, and time constraints must be considered. Location may be dictated by the need for data in a specific area or for a given fish population, proximity to a port and/or access to vessels that can reach distant locations, and the degree to which a given sampling area is representative of other areas. Sampling units within the survey areas can be delineated based on a variety of factors, including environmental gradients (Van Nguyen and Phan 2008), bathymetry, substrate, ease of access, and fish abundance.

During the second round of workshops, federal stock assessment scientists noted that for CCFRP data to be used in standard stock assessment models—such as those conducted by state and federal management agencies in California-the data needed to be collected over broad spatial and temporal scales using standardized protocols (Dr. Steve Ralston, National Oceanic and Atmospheric Administration, Southwest Fisheries Science Center, personal communication). These criteria affected the decisions made about the location of sampling sites and frequency of sampling. For our survey data to be useful for stock assessments, we distributed our effort across as broad a geographic region as we could. We included 4 of the 29 central California MPAs that went into effect in 2007 (CMLPA 2007): the Año Nuevo State Marine Conservation Area (SMCA) and the Point Lobos, Piedras Blancas, and Point Buchon State Marine Reserves (SMRs; Figure 1), which cover nearly $400 \mathrm{~km}$ along the coast. These sites were chosen because (1) they span the breadth of the central California MPA region and (2) because the nearshore rocky habitats within them are extensive and broadly representative of rocky habitats along the central California coastal region. These sites are also popular fishing areas for both recreational and commercial fishermen and are near ports with CPFVs. Furthermore, a portion of the Point Lobos SMR has been closed to fishing since 1973 (McArdle 1997). Therefore, including the Point Lobos SMR as a sampling site allowed us to compare fish assemblages in an area that has been closed to fishing for more than three decades with those in a newly established MPA. In addition to the MPAs, corresponding reference sites were selected for sampling. Each reference site was chosen with the criteria that it shares similar size, habitat, bathymetry, and oceanographic conditions with the MPA but is far enough away to minimize the potential that fish populations inside the reference site were greatly influenced by the MPA (e.g., by spillover from the MPA). Collaborating fishermen were helpful in choosing appropriate survey areas and reference sites for the MPAs by applying their extensive knowledge of the historic fishing activity at the sites and the available habitat.

Within the selected MPAs, $500 \mathrm{~m} \times 500 \mathrm{~m}$ grid cells delineated the survey area. In order to determine the placement 
of the grid cells, we provided the collaborating CPFV captains with nautical charts and asked them to draw polygons, identifying locations with suitable fish habitat within water that was shallower than $40 \mathrm{~m}$ (to limit fishing mortality from barotrauma). We also asked that they indicate areas that were logistically infeasible to sample (Figure 3 ). The grid cells were created from their suggestions along with side scan sonar and bathymetry data.

\section{Develop a Sampling Plan: Create and Evaluate Protocols}

Once the survey objectives, location, and scope have been determined, the details of the project can be discussed, including the sampling protocols and time frame for the project. At this stage, it is important to consider fishermen's availability, weather conditions, cost effectiveness, and the ecology of target species. If planned sampling events conflict with commercial fishing activity, as was the case with the CCFRP, fishermen will need to be adequately compensated.

To encourage discussion and debate and to engage the scientific and fishing communities in the development of the protocols produced by the CCFRP, we held a third series of workshops. Attendees included the primary collaborators as well as secondary collaborators from state and federal management agencies, universities, NGOs, recreational and commercial fishing communities, and the general public. Collaborators were able to comment on the scientific rigor and feasibility of the protocols and usability of the data for management. The resultant survey design reflected an optimal balance between logistical fishing capabilities and scientific sampling needs.

To determine an appropriate number of survey days we approximated how many fish would be caught in a given amount of time based on data from a similar project that we had conducted in prior years. We relied on fishermen's knowledge and historic catch and weather data to determine the time of year to conduct the surveys. At the completion of each survey year we evaluated the coefficient of variation of catch rates with regard to the number of survey days to determine the number of days needed to minimize variability in mean catch per unit effort without oversampling. The mean daily catch rate of all caught fish was used to generate catch per unit effort and coefficient of variation (CV) values for a range of hypothetical sampling periods ( 1 to 20 days) using resampling statistics (Resampling Stats 6.0). Based on 2007-2009 data, we found that, in all four MPA and reference pairs, sampling for 2 days yielded a CV less than or equal to 0.5 for $40 \%$ of the 10 most frequently caught species; 3 days provided a $\mathrm{CV}$ of less than or equal to 0.5 for more than half of the abundant species; and 6-9 days of sampling were needed to reduce the $\mathrm{CV}$ to less than or equal to 0.25 for abundant species. For uncommon species, 15 days or more were needed to obtain CVs of less than 0.25 .
A stratified random sampling design (Conquest et al. 1996) was used to take into account nonrandom, patchy fish distribution patterns. We incorporated fishermen's knowledge by factoring in their assessments of the presence of fish habitat and then stratifying the survey area into grid cells based on habitat. Within the restriction of the grid cells, the captain completed standardized fishing drifts (Wendt and Starr 2009).

Fishing for the survey was done by volunteer recreational anglers. We required that all volunteer anglers be experienced with ocean fishing, over the age of 16 , and capable of fishing for the duration of the survey. The strength of the research then depended, in part, on the ability to recruit skilled fishermen who wanted to be involved in the study. In order to recruit volunteers, ads for the MPA surveys were placed on local fishing websites and in newspapers and flyers were posted near tackle shops and harbors, and we spread the word to collaborators from past projects and to fishing clubs.

The tackle used to catch the fish was determined based on discussions with fishermen at the protocol development workshops and the requirement that the gear reflect the fish population that was intended for surveying and the habitat in which they live. Because suggestions ranged along the study area and by individual, we chose three different types of tackle to ensure that a range of regional preferences was included: red and white shrimp flies (half of each) with and without squid bait and iron lures (called "lingcod bars" in central California). Each gear type was used with equal effort.

In our project, an assessment of the MPA monitoring protocols and the size and placement of the survey grid cells was made during the initial sampling trips. This led to deleting or moving the location of some grid cells, restricting the number of volunteer anglers to 12 per boat due to feasibility of processing fish rapidly and without harm, and adjusting the survey operations (e.g., work flow, delegation of tasks, placement of survey equipment) to be more efficient and to improve fish handling. Based on collaborating fishermen's suggestions during these initial trips, we decided to document and assess additional variables (e.g., tide, wind speed, surface and bottom water temperature, presence of marine mammals, etc.) that might affect catch and mask temporal variability related to changes in fish populations. These pilot surveys also enabled us to spread the word about the project, showing the work in practice to potential volunteers.

\section{Implement the Project: Conduct Standardized Sampling}

In order to make comparisons among areas and over time, sampling protocols must be designed and executed in a standardized manner. To meet this requirement, all people involved in sampling operations should be trained on the protocols and species identifications through workshops that occur prior to 
sampling on the water. We also found that it should be established in advance who among the collaborators will act as the lead fisherman (generally the captain) and scientist on a research cruise. The two leads often consult one another during a trip and have authority to make critical decisions as issues arise (e.g., when to end a trip due to inclement weather), thereby maintaining the flexibility needed to safely perform research at sea.

In our MPA surveys, care was taken to use standard methods, and the protocols were set up such that they were easily repeatable from year to year and area to area. To promote standardization, workshops were held by the lead scientist before sampling began in order to familiarize the scientific crew with the protocols and common fish species (captains were also invited). The science crew practiced measuring, tagging, and "venting" (releasing air from an inflated swim bladder) on dead fish, quizzed on species identification, and became familiar with all sampling instruments (e.g., Secchi disc, water temperature sensor, fish release devices, etc.). During these workshops, the science crew was also given data sheets so that they knew what information needed to be gathered and in what order (e.g., start time and start location needed to be written down in a timely fashion).

\begin{tabular}{|c|c|c|c|c|c|}
\hline & Year & $\begin{array}{l}\text { No. survey days } \\
\text { MPA/REF }\end{array}$ & $\begin{array}{l}\text { Angler hours } \\
\text { MPA/REF }\end{array}$ & $\begin{array}{l}\text { Fishes caught } \\
\text { MPA/REF }\end{array}$ & $\begin{array}{l}\text { No. species } \\
\text { MPA/REF }\end{array}$ \\
\hline \multirow[t]{5}{*}{ Año Nuevo } & 2007 & $5 / 6$ & $85 / 130$ & $356 / 919$ & $16 / 17$ \\
\hline & 2008 & $6 / 6$ & $163 / 164$ & $1,032 / 920$ & $16 / 19$ \\
\hline & 2009 & $4 / 4$ & $100 / 117$ & $732 / 941$ & $19 / 15$ \\
\hline & 2010 & $4 / 4$ & $131 / 119$ & $903 / 1,048$ & $17 / 14$ \\
\hline & Total & $19 / 20$ & $479 / 530$ & $3,023 / 3,828$ & $22 / 23$ \\
\hline \multirow[t]{5}{*}{ Point Lobos } & 2007 & $6 / 6$ & $154 / 137$ & $2,923 / 1,254$ & $19 / 18$ \\
\hline & 2008 & $6 / 6$ & $164 / 192$ & $2,331 / 869$ & $18 / 18$ \\
\hline & 2009 & $4 / 4$ & $100 / 95$ & $700 / 305$ & $15 / 13$ \\
\hline & 2010 & $4 / 4$ & $118 / 90$ & $844 / 374$ & $14 / 15$ \\
\hline & Total & $20 / 20$ & $536 / 514$ & $6,798 / 2,802$ & $21 / 21$ \\
\hline \multirow[t]{5}{*}{ Piedras Blancas } & 2007 & & & & \\
\hline & 2008 & $6 / 6$ & $167 / 141$ & $1,526 / 1,286$ & $21 / 21$ \\
\hline & 2009 & $4 / 4$ & $91 / 90$ & $578 / 437$ & $19 / 19$ \\
\hline & 2010 & $4 / 4$ & $125 / 129$ & $579 / 482$ & $15 / 18$ \\
\hline & Total & $14 / 14$ & $383 / 360$ & $2,683 / 2,205$ & $22 / 25$ \\
\hline \multirow[t]{5}{*}{ Point Bunchon } & 2007 & $6 / 6$ & $172 / 158$ & $1,546 / 930$ & $21 / 18$ \\
\hline & 2008 & $6 / 6$ & $150 / 170$ & $1,098 / 923$ & $19 / 20$ \\
\hline & 2009 & $4 / 4$ & $95 / 108$ & $377 / 322$ & $18 / 17$ \\
\hline & 2010 & $4 / 4$ & $124 / 116$ & $636 / 309$ & $19 / 16$ \\
\hline & Total & $20 / 20$ & $541 / 552$ & $3,657 / 2,484$ & $24 / 24$ \\
\hline \multicolumn{2}{|l|}{ Total MPA/REF } & $73 / 74$ & 1,939/1,959 & $16,161 / 11,319$ & $32 / 35$ \\
\hline \multicolumn{2}{|l|}{ Grand total } & 147 & 3,898 & 27,480 & 39 \\
\hline
\end{tabular}

Surveys were conducted in 2007, 2008, 2009, and 2010, for a combined total of 147 sampling days in four MPAs and four reference sites. During the course of the project, we worked with $16 \mathrm{CPFV}$ captains, 42 deckhands, and over 500 volunteer anglers. Over the four survey years, over 27,000 fishes were caught, representing 39 species (Table 1). Within each MPA and reference site, information was collected on catch rate, species composition, and fish lengths. These data will be used both to evaluate the potential impacts the MPAs have on the nearshore fish assemblages and to contribute to localized stock assessments.

We are now planning to work with resource management agencies to incorporate our data into fishery-sustainability models that rely upon comparisons of fish densities inside and outside closed areas. Some analyses we plan to conduct with our data include an MPA decision-tree approach (Wilson et al. 2010), an MPA density ratio method (Babcock and MacCall 2011; McGilliard et al. 2011), a length-based referencepoint model (Cope and Punt 2009), a size-based methodol- ogy, and a model that uses length frequency distributions to estimate the fraction of lifetime egg production (O'Farrell and Botsford 2005). Moreover, in order to assess changes in catch rates, mean lengths, and length frequency of individual species, comparisons will be made between the MPA and reference site pairs over time (Figure 4). These data will also be used to assess changes in species composition over time. Currently, species composition between each MPA and reference site is more similar than among the MPAs (Figure 5), with significant differences among areas (permutation multivariate analysis of variance, $P=0.0001)$. This is expected given the disparate habitat types along the central California coast (Norris and Webb 1990; Wagner et al. 2002; Kvitek 2010).

\section{Evaluate the Project: Review Results and Protocols}

To be fully successful, collaboration should extend beyond the data collection process. As in the preceding steps of the project, fishermen should be involved in reviewing the pro- 

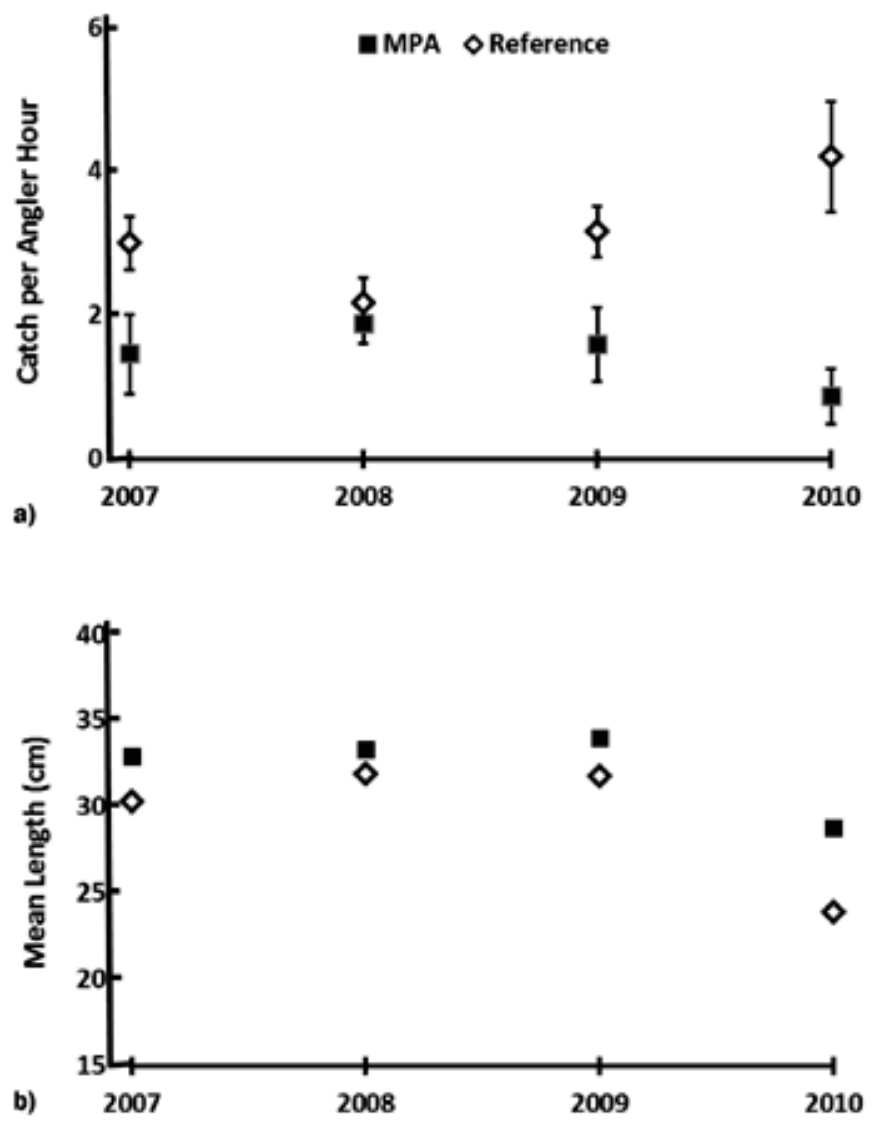

Figure 4. Comparing the (a) catch rate (catch per angler hour) and (b) mean lengths (plus or minus standard error) of black rockfish (Sebastes melanops) in the Año Nuevo State marine conservation area and corresponding reference site over the four survey years. This is an example of how our data will serve as a baseline for future comparisons and, with additional years of data, will indicate changes in the MPA with respect to an open area. Note that catch rate and mean length for 2010 were greatly affected by catches of a large number of 20 - to $25-\mathrm{cm}$-long (2- to 3-year-old) individuals.

tocols and results, suggesting ways to improve the execution of the research. Time should be taken to show collaborating fishermen how the data are being stored and how rigorously they are audited and quality controlled (e.g., checking for data recording and entry errors and being aware of data that should not be used for analysis due to errors in sampling). Data should also be made available to fishermen and other collaborators in order to maintain transparency. Furthermore, collaborators should collectively review the protocols and discuss the success of the project and the desire and potential to increase involvement for collaborators.

We held a series of workshops in each region at the completion of each MPA survey field season to evaluate the project and to discuss data analysis (Figure 3). At these meetings, both primary and secondary collaborators offered suggestions on how to improve upon the project. Collaborating fisheries managers suggested ways in which the data could be used for management and, along with other collaborating scientists, recommended analyses for evaluating the data.

\section{Communicate the Results: Maintain Relationships with Broad Outreach}

Collaborative research has the ability to bridge disparate communities through frequent and open communication. This communication should not end after a survey is designed, executed, and evaluated. Rather, correspondence among primary and secondary collaborators and the general public should be maintained throughout the course of the project and, when possible, after its completion. Indeed, an open line of communication strengthens relationships, promotes involvement in future collaborative efforts, and can be practically beneficial to the research efforts when, for example, the survey relies upon members of the fishing community to report tagged fishes. It is valuable to look for ways to implement the data into a management system, sharing the data with collaborating resource managers. Moreover, it is clear from previous studies and our experience that information should be published in a style that can be understood by industry members as well as scientists (Steneck 2006; Johnson and van Densen 2007) and that it needs to be tailored for a variety of different audiences. For example, newsletters are useful, especially when fishermen do not have access to the Internet or if they do not use it frequently (Gilden and Conway 2002). Newsletters are also more person$\mathrm{al}$, and the effort relays the message that the communication is important. However, creating a newsletter is time consuming and it is a slow method for disseminating information; thus, other forms of communication are also valuable (Gilden and Conway 2002). Regardless of the method(s) used, information must be circulated broadly to multiple, diverse communities, representative of the stakeholders and collaborators involved, and to the general public.

During and after the CCFRP surveys, a substantial effort was expended to conduct outreach activities. Time was taken to meet with scientists from fisheries management agencies to discuss the data and ways in which they could be incorporated into management, especially into stock assessments and evaluation of the MPAs. Furthermore, e-mails and annual flyers were sent to the volunteer anglers (Figure 6), project updates were posted on fishing websites, presentations were given to community groups, and press releases were done with traditional sources of media (local newspapers, TV news, etc.). In addition, information about the study was posted on two websites (http://seagrant.mlml.calstate.edu/research/ccfrp/ and http:// slosea.org/initiatives/sf/baseline.php), including a project overview, a description of the study areas (including maps), sampling results, volunteer sign-up information, media related to the project, information on what to do with a recaptured tagged fish, and photos of the people involved. Through this outreach, the project experienced an increase in the number of fishermen each year, with many fishermen volunteering repeat- 


\section{Año Nuevo SMCA 2007-2010}

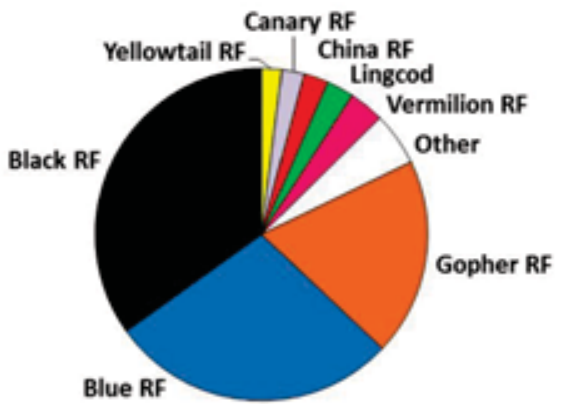

Piedras Blancas SMR 2008-2010

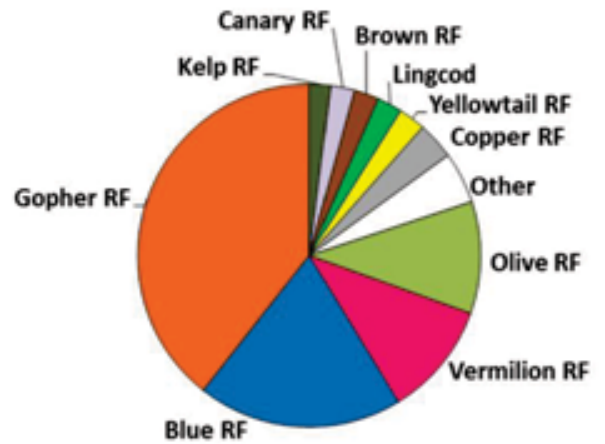

\section{Point Lobos SMR 2007-2010}

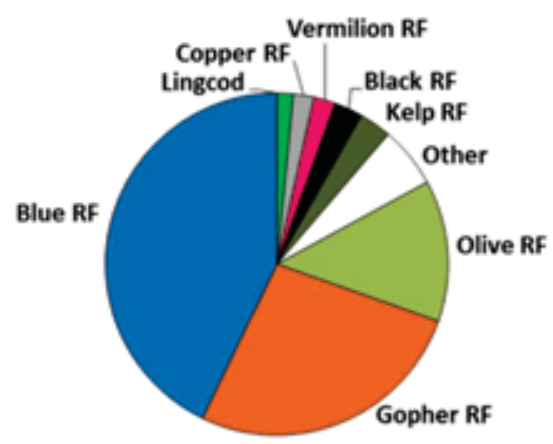

Point Buchon SMR 2007-2010

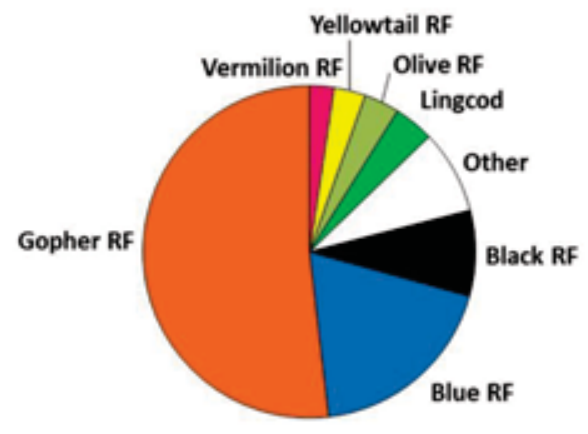

Figure 5. Species composition of the four survey areas summed over all survey years (2007-2010) with both MPA and reference sites combined. Fishes include lingcod (Ophiodon elongatus) and the following rockfishes (RF): black (Sebastes melanops), blue (S. mystinus), brown (S. auriculatus), canary (S. pinniger), China (S. nebulosus), copper (S. caurinus), gopher (S. carnatus), kelp (S. atrovirens), olive (S. serranoides), vermilion (S. miniatus), and yellowtail (S. flavidus). All species comprising less than $1.5 \%$ of the total catch in a given area were grouped into the "other" category.

edly. For example, 22 individuals volunteered for more than 10 days, and one volunteered for 35 days.

\section{Discussion \\ Conflict Resolution}

Despite the tension that existed among stakeholder groups and between resource users and government as a result of California's MPA implementation process, we found that many fishermen were willing and active participants in the CCFRP research program. Moreover, though some of the volunteer anglers belonged to organizations that were suing the state over the MPAs and were skeptical of the reserves, we found that they participated and supported our efforts and gave positive reviews of their experiences working on the project. That being said, our collaborative research program did not go entirely without conflict or opposition. For example, in talking with a local fisherman we learned that a rumor existed that our tag return program was a way to trap fishermen who were fishing inside of the closed areas. Similarly, several fishermen called about reporting tagged fishes but claimed that it was not worth it to them to report tags given the small reward $(\$ 20$, a sticker, and a letter about the fish they caught). In both cases, we simply tried

to spread the word about the importance of the information and to clear up misconceptions. Additional conflict arose because of pricing discrepancies among ports for charters to pay for sampling trips. Even with effort to standardize costs, market forces dictated that we pay different rates in different areas at times. This resulted in some animosity among collaborators, although we relied on careful explanation and transparency to resolve the conflict. Conflicts also arose within ports where we had more interested owners and captains than we could charter. In an attempt to maintain equity among the fleet, we spread the limited survey days among the captains who were willing to attend meetings and to work collaboratively. Another concern arose from our choice of tackle. We received several phone calls about different tackle that we should be using. Here, again, we explained to callers the rationale behind our decision while also listening to and-where possible-making some modifications based on their advice. We purchased tackle from local producers whose names were widely known, so the "brand recognition" helped to assuage some of this criticism. Another problem that arose was that some captains and deckhands wanted to tag, measure, and vent the fish. We acknowledged that the fishermen wanted to help but also tried to make it clear that it was important for the delegated roles to be respected and that the scientists maintain their task of using standardized techniques to handle, assess, and tag the fishes. When the fishermen did not respect these boundaries, we ensured that the fishes were processed appropriately. Similarly, it sometimes proved challenging to get the volunteer anglers to keep the fish alive given that they typically kept their caught fish. To make this point clear, we discussed the importance of taking care not to injure the fishes in our morning speech and asked the deckhands to crimp down the hook barbs and alert fishermen to when they were being careless. In general, the criticism and conflict that we encountered was almost always satisfied by listening to the person and then explaining what we were doing and why. It was also helpful to talk to people in the resource user community to get a sense of their perceptions of the research and to learn the germane issues. 


\section{Evaluation}

Though we clearly promote the use of collaborative research, we recognize that there is the potential for cooperation to have negative outcomes or result in outcomes where it would have been advantageous for scientists to have completed the work alone. As demonstrated by Schumann (2010), there is the potential for increased participation by resource users to increase deference and trust in science to the point where fishermen no longer feel a need for collaboration or, on the contrary, the fishermen are involved too much and begin to resent scientists for imposing on them a hefty work load.

We also acknowledge that, at times, a cooperative approach - with fishermen involved in fewer steps-may be more appropriate (e.g., when time, interest on the part of fishermen, or funding is limited). For the MPA surveys that were conducted, several key components made it possible for us to involve fishermen throughout the process, namely, (1) there was consistent funding for this research; (2) there was a dedicated technician on the project; (3) relationships among many of the collaborators existed prior to the beginning of the project; and (4) fishermen and scientists in the study region are typically forward thinking, making it relatively easy to find interested collaborators.

Despite these advantages, there were still areas where we could have improved. For example, it would have been advantageous to survey the collaborating managers, scientists, captains, and volunteer anglers before and after their involvement with the project to see how their participation influenced their perceptions of one another and the MPAs and to understand how their relationships with respect to trust and camaraderie changed. Without surveys, it is difficult for us to quantify the success of the research in this regard. However, we feel that the captains' and volunteers' continued commitment to the project (e.g., 15 workshops to date, each with an average of 20 attendees), the friendships that developed, and the investment of the fishermen are all indications of a successful collaboration. Moreover, many of our volunteer anglers put CCFRP bumper stickers on their cars, wore CCFRP hats, and some of them defended our research and MPAs to fishermen on local fishing websites. In addition, some of the collaborating captains asked to use the data to take to management meetings, thereby acknowledging that the data were valuable. Furthermore, we have received unprompted phone calls from fishermen relating their on-the-water observations to previous discussions of data. One of our collaborating captains called to say that "catch rates of blue rockfish seem to be trending the way we predicted from the previous year."
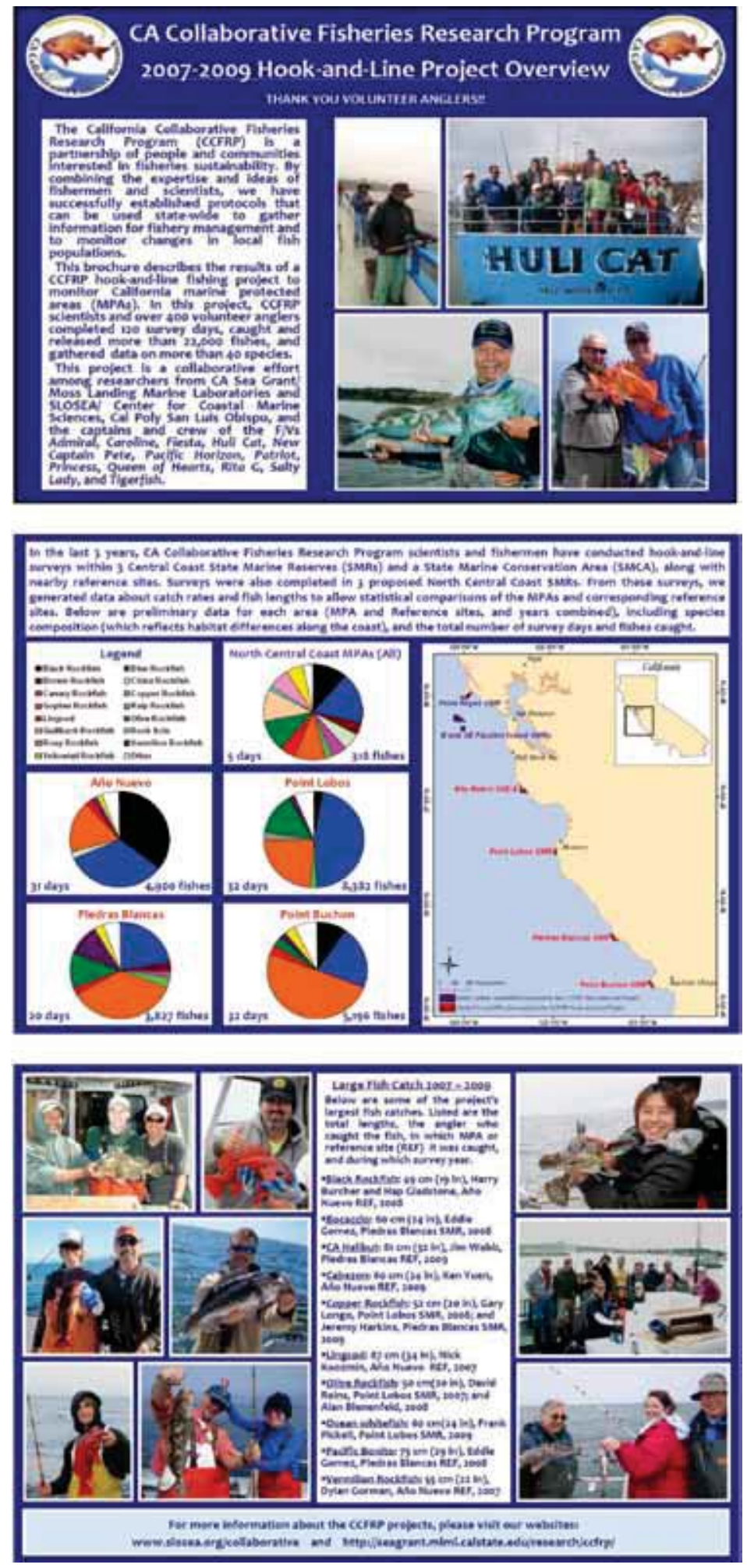

Figure 6. At the completion of each survey year, a summary flyer was mailed to all volunteers and collaborating captains. This was the flyer that was mailed at the end of the $\mathbf{2 0 0 9}$ survey year. Included on the back page of the flyer (not shown here) was a thank-you message and personalized information for each volunteer, including their name, the total number of days they volunteered, and their total catch. 


\section{Conclusions}

The research conducted by the CCFRP demonstrates the advantages of collaboration between fishermen and scientists. The surveys generated data that respond to the need for baseline information on the central California MPAs for future evaluation of their impacts on nearshore fishes and will inform the larger study of MPA effects. These surveys were also able to assess fish populations that are cryptic, rock dwelling, and difficult to study and generated data that could be utilized in stock assessments to determine the status of localized substocks. Because the survey design is applicable all along the coast, it allows for the collection of comparable data in multiple states and regions as additional MPAs are established in California.

The CCFRP surveys also highlight the ability of collaborative research projects to facilitate communication and trust building between scientists and fishermen. We feel that the collaborative approach used in this study is incredibly advantageous for fisheries research and we hope that the described methodology can serve as a model to assist in the creation of future collaborative projects.

\section{Acknowledgments}

This research was made possible by the investment and dedication of the collaborating CPFV captains (Joe Anderton, Dennis Baxter, Sergio Bermudez, Michael Cabanes, Allen Chin, Jared Davis, Tony Emge, Lee Gualltieri, Owen Hackelman, Bob Ingles, Joe Kucera, Charlie Lanini, Brad Leage, Michele Leary, David Lemon, Tom Mattusch, Sal Rocha, John Rowley, Dustin Selck, and Roger Thomas), deckhands (Daniel Adams, Evan Beckett, Gary Christensen, James Crissman, Josh Dagama, Zach Davidson, Jonathan Dresser, Matt Duffy, Aldo ElSourgougy, Tom Foss, Frank Garibay, Jay Gavin, Dan Holdsman, Trevor Jenison, Mike Lane, David Lapchuk, Rick Lopez, Sam Mejilla, Andrea Mizera, Nate Moore, Bruce Oda, Brian Pabinquit, Jessica Rohdes, Brian Rowley, Fernando Salazar, Joe Saputo, Larry Schumacher, Darren Seiji, Heather Shirley, Bryan Smith, and Michael Wood), science crews, and hundreds of volunteer anglers. We also acknowledge Don Maruska for serving as facilitator, John Penvenne for website creation and management, David Kammerer for field support, and Tom Barnes, Jason Cope, Rod Fujita, Alec McCall, Royden Nakamura, Steve Ralston, John Stevens, and Deb Wilson-Vandenberg for attending workshops and providing input on technical aspects of the project. We thank the California Coastal and Marine Initiative of the Resources Legacy Fund Foundation, the California Ocean Protection Council, the California Sea Grant College Program, the David and Lucile Packard Foundation, and the Keith Campbell Foundation for the Environment for funding this research.

\section{References}

Babcock, E., and A. MacCall. 2011. How useful is the ratio of fish density outside versus inside no-take marine reserves as a metric for fishery management control rules? Canadian Journal of Fisheries and Aquatic Sciences 68:343-359.

CDFG (California Department of Fish and Game). 2008. California Marine Life Protection Act. Master plan for marine protected areas. Revised draft. Available: http://www.dfg.ca.gov/mlpa/pdfs/ revisedmp0108.pdf. Accessed January 5, 2009.

CDFG (California Department of Fish and Game). 2011. Marine Life Protection Act. Available: http://dfg.ca.gov/mlpa. (July 2011).

CMLPA (California Marine Life Protection Act Initiative). 2007. Guide to the central California marine protected areas Pigeon Point to Point Conception.

Conquest, L., R. Burr, R. Donnelly, J. Chavarria, and V. Gallucci. 1996. Sampling methods for stock assessment for small-scale fisheries in developing countries. Pages 179-225 in V. F. Gallucci, S. B. Saila, D. J. Gustafson, and B. J. Rothschild, editors. Stock assessment: quantitative methods and applications for small-scale fisheries. CRC Press, New York.

Conway, F. D. L., and C. Pomeroy. 2006. Evaluating the human-as well as the biological-objectives of cooperative fisheries research. Fisheries 31:447-454.

Cope, J. M., and A. E. Punt. 2009. Length-based reference points for data-limited situations: applications and restrictions. Marine and Coastal Fisheries: Dynamics, Management, and Ecosystem Science 1:169-186.

Daw, T. M., J. Robinson, and N. A. J. Graham. 2011. Perceptions of trends in Seychelles artisanal trap fisheries: comparing catch monitoring, underwater visual census and fishers' knowledge. Environmental Conservation. 38: 75-88.

Feeney, R. G., K. J. La Valley, and M. Hall-Arber. 2010. Assessing stakeholder perspectives on the impacts of a decade of collaborative fisheries research in the Gulf of Maine and Georges Bank. Marine and Coastal Fisheries: Dynamics, Management, and Ecosystem Science 2:205-216.

Gilden, J., and F. Conway. 2002. An investment in trust: communication in the commercial fishing and fisheries management communities. Oregon Sea Grant Publication ORESU-G-01-004, Oregon State University, Corvallis, Oregon.

Harms, J. and G. Sylvia. 2000. The economics of cooperative fishery research: a survey of U.S. West Coast groundfish industry and scientists. 10 pages. In: Microbehavior and Macroresults: Proceedings of the Tenth Biennial Conference of the International Institute of Fisheries Economics and Trade, July 10-14, 2000, Corvallis, Oregon, USA. Edited by Richard S. Johnston and compiled by Ann L. Shriver. International Institute of Fisheries Economics and Trade (IIFET), Corvallis, OR, 2001. http://www. st.nmfs.noaa.gov/st5/documents/The_economics_of_cooperative_fishery_research.pdf

Hart, A. M., F. P. Fabris, J. Brown, and D. Murphy. 2008. Digital video surveys of abalone (Haliotis sp.) stocks by commercial fishers in western Australia. Fisheries Research 93:305-314.

Hartley, T. W., and R. A. Robertson. 2006. Emergence of multi-stakeholder-driven cooperative research in the northwest Atlantic: the case of the Northeast Consortium. Marine Policy 30:580592.

Hartley, T. W., and R. A. Robertson. 2008. Cooperative research program goals in New England: perceptions of active commercial fishermen. Fisheries 33:551-559. 
Hartley, T. W., and R. Robertson. 2009. Stakeholder collaboration in fisheries research: integrating knowledge among fishing leaders and science partners in northern New England. Society and Natural Resources 22:42-55.

Johnson, T. R. 2010. Cooperative research and knowledge flow in the marine commons. International Journal of the Commons $4: 251-272$.

Johnson, T. R., and W. L. T. van Densen. 2007. Benefits and organization of cooperative research for fisheries management. ICES Journal of Marine Science 64:834-840.

Jones, A., S. J. Slade, A. J. Williams, B. D. Mapstone, and K. J. Kane. 2007. Pitfalls and benefits of involving industry in fisheries research: a case study of the live reef fish industry in Queensland, Australia. Ocean \& Coastal Management 50:428-442.

Kaplan, I. M., and B. J. McCay. 2004. Cooperative research, co-management and the social dimension of fisheries science and management. Marine Policy 28:257-258.

Kvitek, R. 2010. Seafloor Mapping Lab remote imagery. Available: http://seafloor.csumb.edu/index.html. (Accessed May 2010).

Maienschein, J. 1993. Why collaborate? Journal of the History of Biology 26:167-183.

McArdle, D. A. 1997. California marine protected areas. California Sea Grant College System Publication T-039, University of California, La Jolla, California.

McGilliard, C. R., R. Hilborn, A. MacCall, A. E. Punt, and J. C. Field. 2011. Can information from marine protected areas be used to inform control-rule-based management of small-scale, data-poor stocks? ICES Journal of Marine Science 68:201-211.

Norris, R. M., and R. W. Webb. 1990. Geology of California, 2nd edition. John Wiley \& Sons, New York.

NRC (National Research Council). 2004. Cooperative research in the National Marine Fisheries Service. National Academies Press, Washington, D.C.

O'Farrell, M. R., and L. W. Botsford. 2005. Estimation of change in lifetime egg production from length frequency data. Canadian Journal of Fisheries and Aquatic Sciences 62:1626-1639.

Pinto da Silva, P., and A. Kitts. 2006. Collaborative fisheries management in the Northeast U.S.: emerging initiatives and future directions. Marine Policy 30:832-841.

Rochet, M.-J., M. Prigent, J. A. Bertrand, A. Carpentier, F. Coppin, J.P. Delpech, G. Fontenelle, E. Foucher, K. Mahé, E. Rostiaux, and V. M. Trenkel. 2008. Ecosystem trends: evidence for agreement between fishers' perceptions and scientificinformation. ICES Journal of Marine Science 65:1057-1068.

Schumann, S. 2010. Application of participatory principles to investigation of the natural world: an example from Chile. Marine Policy 34:1196-1202.

Silver, J. J., and L. M. Campbell. 2005. Fisher participation in research: dilemmas with the use of fisher knowledge. Ocean \& Coastal Management 48:721-741.

Steneck, R. S. 2006. Sea Grant 3rd annual science symposium, lobsters as model organisms for interfacing behavior, ecology, and fisheries: discussion session summary on cooperative research. Journal of Crustacean Biology 26(4):663-665.

Tuckey, T., N. Yochum, J. M. Hoenig, D. A. Hepworth, J. Lucy, R. O'Reilly, and J. Cimino. 2007. Evaluating localized vs. largescale management: the example of tautog in Virginia. Fisheries 32:21-28.

Van Nguyen, L., and H. K. Phan. 2008. Distribution and factors influencing on structure of reef fish communities in Nha Trang Bay marine protected area, south-central Vietnam. Environmental Biology of Fishes 82:309-324.

Wagner, D. L., H. G. Greene, G. J. Saucedo, and C. L. Pridmore. 2002. Geologic map of the Monterey $30 \times 60$ quadrangle and adjacent areas, California. California Department of Conservation, California Geological Survey.

Wells, S., M. Samoilys, S. Makoloweka, and H. Kalombo. 2010. Lessons learnt from a collaborative management programme in coastal Tanzania. Ocean \& Coastal Management 53:161-168.

Wendt, D. E., and R. Starr. 2009. Collaborative research: an effective way to collect data for stock assessments and evaluate marine protected areas in California. Marine and Coastal Fisheries: Dynamics, Management, and Ecosystem Science 1:315-324.

Wiber, M., A. Charles, J. Kearney, and F. Berkes. 2009. Enhancing community empowerment through participatory fisheries research. Marine Policy 33:172-179.

Wilson, J., J. Prince, R. Jeremy, D. Lenihan, and S. Hunter. 2010. A management strategy for sedentary nearshore species that uses marine protected areas as a reference. Marine and Coastal Fisheries $2: 14-27$.

\section{From the Archives}

We may not indulge in the dainties of the Roman epicure who displayed his many hued beauties alive to his guests, before cooking and serving; but for abundant food and plucky game, for marvelous breeding and wonderful distribution, no devices compare with those of our own time and country. By new modes of transit, frozen mulletare brought from New Zealand to be sold in old England, and live carp are sent in tanks over car-wheels from Washington to Dakota and Texas. Under the name of Kennebec salmon, large quantities of salmon from rivers of the Pacific slope are being sold at this moment in New York, and even by dealers in Washington markets. The little blueback (Oncorhynchusnerka) and the quinnet (Oncorhynchuschovicha) are now sold in this city at the price of 50 cents per pound. These are brought in refrigerator cars from the Columbia river, Oregon, and are in such a good state of preservation as to pass readily for Maine salmon.

By telegraph to-day, we learn that a car-load of 20,000 salmon from Oregon, is en route for New York, and is to arrive in eight days. This is what may be called the fruit of an enterprise by means of water frozen and water vaporized - ice and steam-for the preservation and transportation of this rarest of fish, fresh from the grand river of our Pacific coast.

S.S. Wilcox, Thirteenth Annual Meeting, American Fish-Cultural Association 